\title{
The use of the Rotoscope as an online, real-time, non-destructive biofilm monitor
}

\author{
T.E. Cloete and M.R. Maluleke
}

\section{Introduction}

Bacterial cells present in the fluid contact the substratum by a variety of transport mechanisms, and once at the substratum, cells can adsorb either reversibly or irreversibly. If the cells remain at the surface for a sufficient time, they secrete extracellular polymers that serve to attach them tenaciously to the substratum. Attached cells metabolise, grow, replicate and produce insoluble extracellular polysaccharides, thus accumulating an initial viable biofilm community (Morton et al., 1998). Bacterial cells of the same or different species continue to be recruited from the fluid and incorporated into the biofilm community. Biofilms develop on any surface in natural soil and aquatic environments, on tissues of plants, animals and humans as well as in man-made systems (Schulte et al., 2005).

Biofilms are evolved in all kinds of biofouling and cause a significant economic loss of billions of dollars annually, worldwide (Gilbert et al., 2003). When they develop on ship hulls, or in industrial pipe systems, they will increase frictional resistance that will lead to a substantial pressure drop (Stoodley et al., 2002) and an increase in energy consumption or to a reduction in the speed of vessels. In cooling water systems, they cause increase in resistance to heat energy transfer. This growth reduces the water quality, increases the pressure differentials in membrane processes, and reduces the efficiency of heat exchangers (Schmid et al., 2004). In some cases, biofilms result not only in the unwanted accumulation of biological material on surfaces, but also promote the precipitation of minerals, such as carbonate; which leads to mixed biological and non-biological deposits that are particularly difficult to remove (Schulte et al., 2005).

Unwanted growth of biofilms in technical processes is a natural phenomenon, due to the favourable conditions of nutrients, temperature and availability of microorganisms (Giao et al., 2003). Five mitigation approaches are currently followed: (a) biofilms are killed by biocides at lethal doses; (b) biofilms are dispersed by dispersants; (c) biofilms are removed physically by a variety of processes; (d) biofilms are weakened by enzymes or chelates; (e) ultraviolet light can also be used to control bacterial numbers (Cloete et al., 1998).

In order to effectively control the growth of biofilms, it is necessary to investigate the structure of biofilms grown under different conditions (Staudt et al., 2003). Several methods are available to monitor biofilm progression (Table 1), but their applications are limited by low intensity, high labour intensity, intrusive sampling, and long time lags from sampling to results (Bakke et al., 2001).

Monitoring of parameters that are evidently related to biofilm accumulation or an effect of biofilm accumulation can help to select the intensity of the measured signal that triggers a warning system, e.g. if the readout exceeds a certain number, (it indicates the presence of biofilm) then add a biocide (Lewandowski and Beyenal, 2003). Many biofilm monitoring systems follow such a preventive strategy, and they act as action triggers. The main objective of this research was to evaluate the Rotoscope for biofilm monitoring.

\section{Material and methods \\ Biofilm reactor}

A schematic diagram of the biofilm Rotoscope reactor used in this study is shown in Figure 1 . The system consists of a tank, which is capable of carrying $20 \mathrm{~L}$ of water when it is full. A rotating plastic wheel (disc) is moved by the water that is pumped from the tank through the discharge side (pipe) back to the tank. The speed of the pump is $4,000 \mathrm{~L} / \mathrm{h}$. The suction side sucks water from the tank, through the pump to the discharge side. The biofilm growing on the rotating disc can be measured on a frequency using the light monitor or sensor. The light monitor measures the light reflected by the biofilm on the disc. This allows one to measure the kinetics of the biofilm deposit and compare it to the biofilm level after 
it has been subjected to a biocide. The flowing water passes through the modified Peterson device in which removable coupons e.g. glass slides are placed for the attachment of microorganisms.

\section{Biofilm growth}

Water was collected from LC dam at the University of Pretoria (SA). Eighteen litres of water was used to grow the biofilm. Biofilm was allowed to grow on the rotating discs and on the removable glass slides, which were placed inside the modified Peterson device. Slides were removed daily and fixed in $10 \mathrm{~mL}$ fixing solution $(2.5 \%$ gluteraldehyde in $0.0075 \mathrm{M}$ phosphate buffer) for SEM. For SEM slides were washed $3 £$ with $0.0075 \mathrm{M} \mathrm{Na}_{2} \mathrm{PO}_{4}$ buffer to remove all the gluteraldehyde. This was followed by the denaturing steps, which were done by washing with $50 \%, 70 \%, 90 \%$ and $100 \%$ ethanol. The last washing (with 100\% ethanol) was repeated $3 \mathrm{X}$ in the interval of $15 \mathrm{~m}$.

Table 1 Devices used to monitor biofilm growth

\begin{tabular}{ll}
\hline Biofilm monitoring technique & Reference \\
\hline Electron microscopy & Cloete et al., 1998; Lazarova and Manem, 1995 \\
Confocal laser scanning microscopy & Staudt et al., 2003 \\
Pedersen's device & Jacobs et al., 1996 \\
Robbin's device & Johnston and Jones, 1995 \\
Rectangular duct biofilm reactor & Bakke et al., 2001 \\
BloGEORGEe & Bruij et al., 2003 \\
Photo-acoustic spectroscopy & Schmid et al., 2004 \\
AQUASIM & Wanner and Morgenroth, 2004 \\
The Roto-torque system & Characklis and Marshall, 1990 \\
Linear polarization resistance & Christiani et al., 2002 \\
Electrochemical impedance spectroscopy & Christiani et al., 2002 \\
Electrochemical noise & Christiani et al., 2002 \\
Biowatch & Ondeo-Nalco \\
Atomic force microscope & Hilal and Bowen, 2002 \\
\hline
\end{tabular}

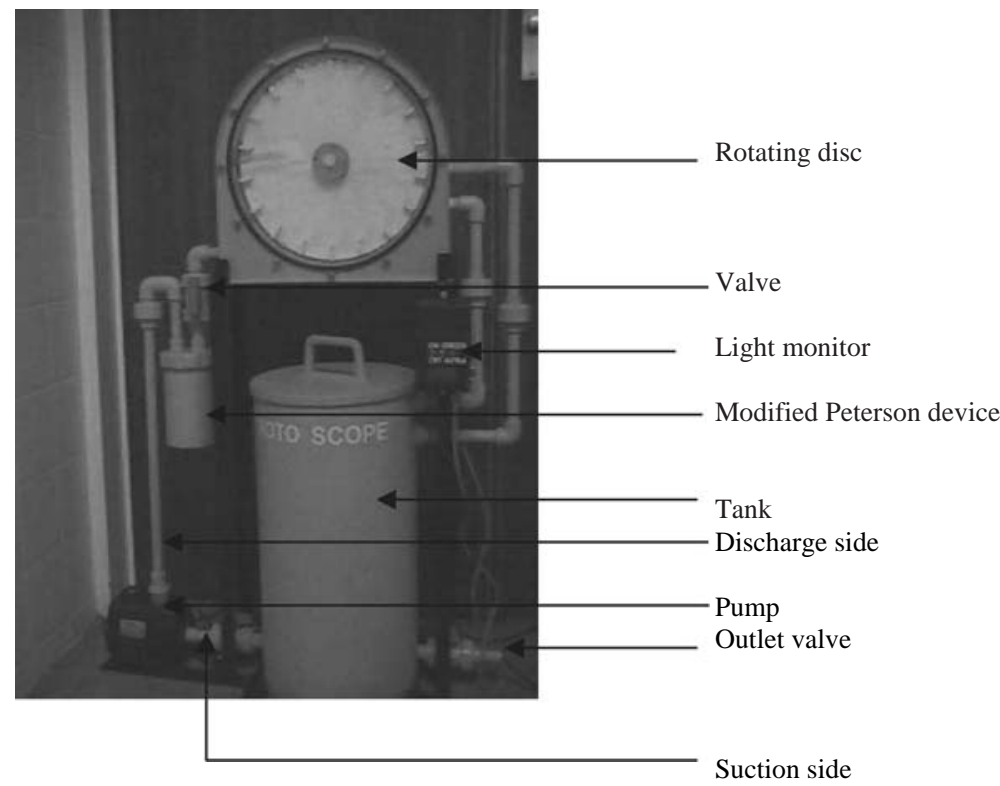

Figure 1 Laboratory Rotoscope used to monitor biofilm growth

The slides were dried using a critical point drying for 5 to 6 hours and coated with gold. Light reflected was recorded daily, and on the 19th day, an anolyte derived from $\mathrm{NaCl}$ (1:10 dilution) was added to the tank. Samples for the SEM were again taken and the light reflected noted. 


\section{Results}

\section{Biofilm growth measured with the Rotoscope}

The decrease in reflected light as a result of biofilm growth on the rotating disc is illustrated in Figure 2. Light reflected started at 60 $\mathrm{mV}$ and decreased over time. The addition of an anolyte as indicated by an arrow (Figure 2) caused the reflectance to increase for a short while, indicating the partial removal of the biofilm, after which it decreased as a result of bacterial regrowth.

\section{Discussion}

The growth of biofilm was monitored using a laboratory Rotoscope reactor. In this study, as the disc was rotating in water, the microorganisms in the water attached to the disc, accumulated with time and led to the formation of biofilm. This resulted in a decrease of the light reflected by the disc.

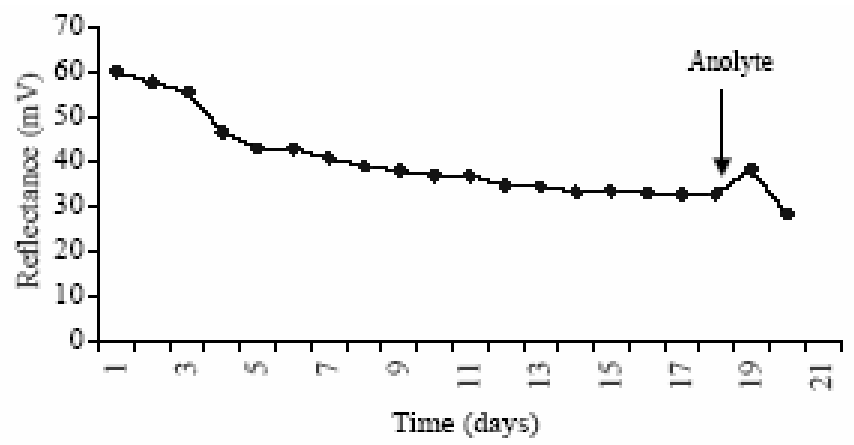

Figure 2 The average reflectance readings as affected by the biofilm on the rotaing disc (the amrow indicates the time anolyte was added)

The decrease in light reflectance was due to the attachment of microbial cells and production of EPS molecules on the surface of the rotating disc (Figure 2). Light reflectance changed with biofilm thickness and the thicker the biofilm, the less light was reflected. Light reflectance is the most common variable monitored in biofilm literature probably because of its simple interpretation and the fact that it can be measured without the use of microscopy (Heydorn et al., 2000). These results are in agreement with a previous study showing that the changes in light reflectance were caused by biofilm thickness (Lewandowski and Beyenal, 2003). The thicker the biofilm, the less light was reflected because biofilm thickness affected the spatial dimensions of the biofilm (Heydorn et al., 2000). A decrease of backscatter light was also observed when a fiber optical device (FOD) was installed in a piping system to indicate the formation of biofilm and the efficacy of cleaning measures (Tamachkiarow and Flemming, 2003). As biofilm thickness increased with time, a critical thickness stage known as the steady-stage was reached. A relatively linear line from day 11 in this study indicated that 


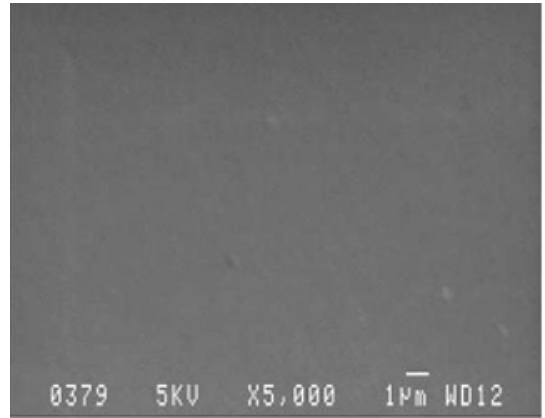

control (clean slide)

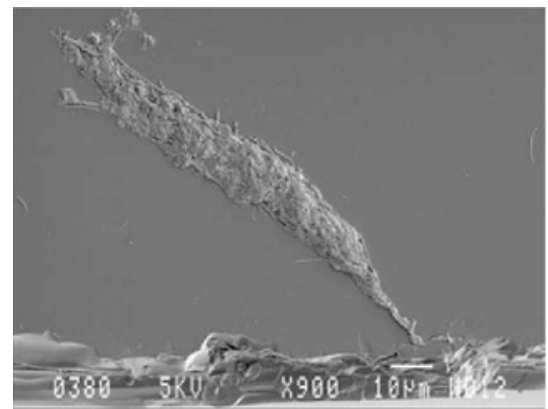

24 hours

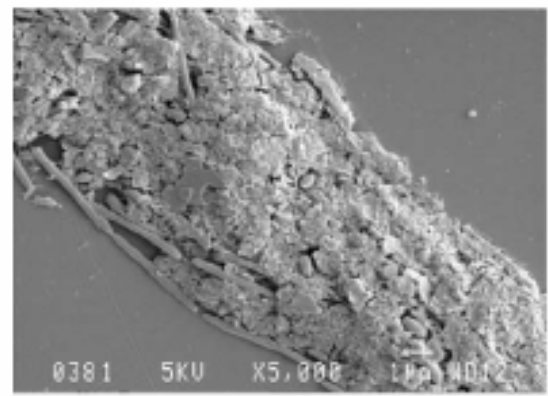

24 hours

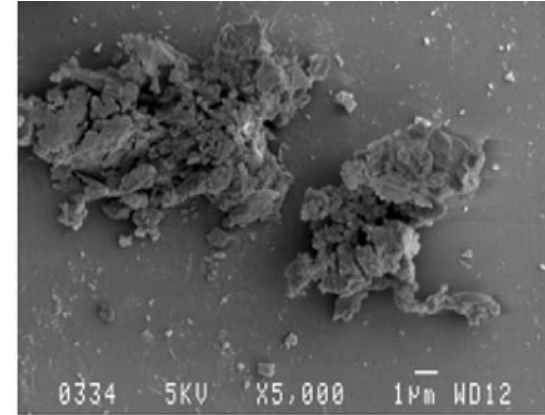

48hours

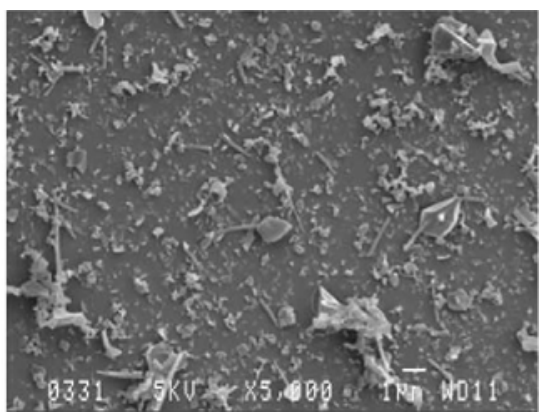

72 hours

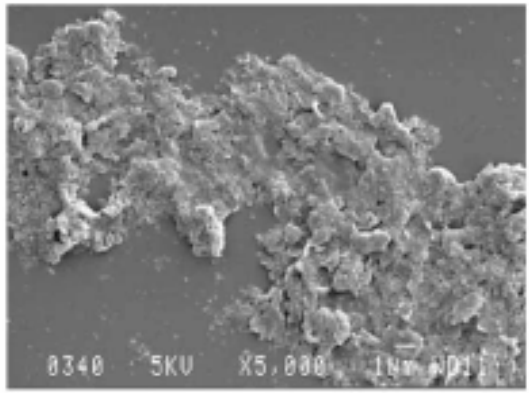

120 hours

Figure 3 SEM micrographs of biofilm growth on glass over first 120 hours

this was happening (Figure 2). Once this stage was reached, microbes covered the entire surface area. This phenomenon results in the underlying region of the biofilm becoming oxygen deficient (anaerobic), allowing the detachment (sloughing) of some microorganisms. At this stage, a steady state between attachment and detachment of cells is reached. In this study, the latter was also observed and supported by the SEM results. SEM indicated that attachment of microorganisms was not uniform. Few cells were initially attached. After $24 \mathrm{~h}$, a large number of microbial cells and EPS were visible. These increased with time until the entire surface area was covered (Figure 3).

The use of biocides to control biofilm growth is a common practice (Cloete et al., 1998). In this study, the effect of $\mathrm{NaCl}$ anolyte on the biofilm was monitored using the Rotoscope. The addition of $\mathrm{NaCl}$ anolyte as a biocide caused some detachment of the microbial cells (Figure 4), indicated by a slight increase in light reflectance (Figure 2). During disinfection, dead biomass will however stay in place and may provide nutrients for the new cells and the incoming cells leading to rapid regrowth of biofilm. In this 


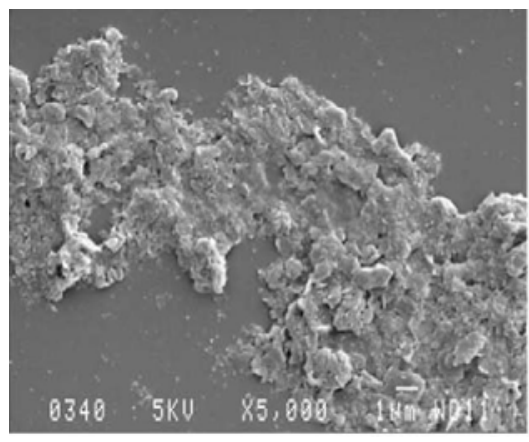

control (120h old biofilm)

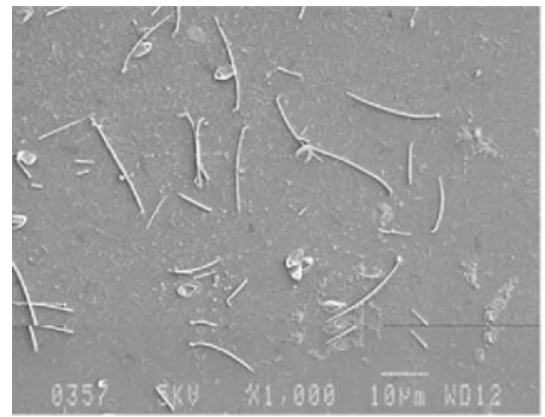

5 min after treatment

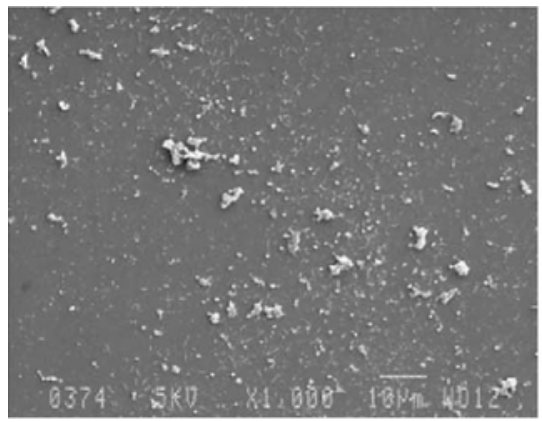

30min after treatment

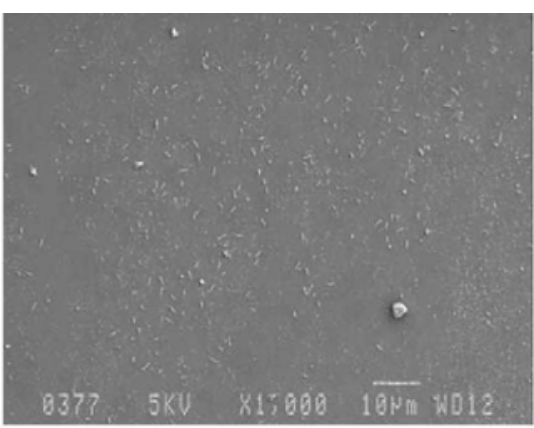

19 hours after treatment

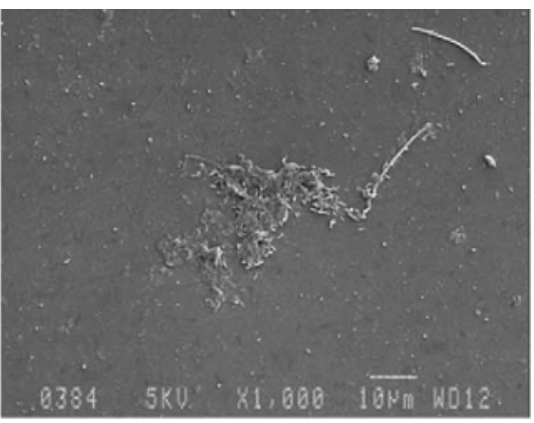

27 hours after treatment

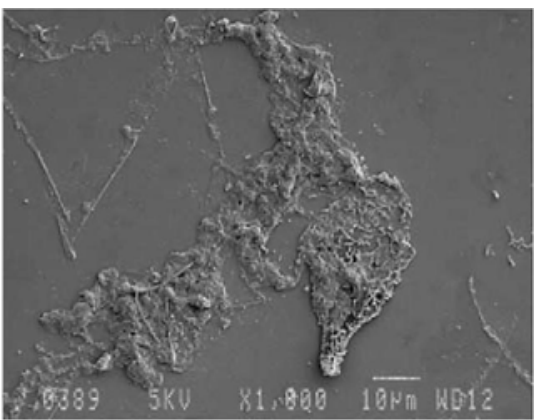

45 hours after treatment

Figure 4 SEM micrographs of biofilm after addition of 1:10 dilution of $\mathrm{NaCl}$ anolyte

study, the decrease in light reflectance, indicating an increase in biofilm formation, was attributed to microbial regrowth.

\section{Conclusions}

The Rotoscope proved to be sensitive to slight changes in biofilm thickness offering an on-line, real-time, non-destructive method for monitoring biofilms. With respect to bio-film research, the Rotoscope offers a significant advantage in that the biofilm can be investigated in an undisturbed state.

\section{References}

Bakke, R., Kommendal, R. and Kalvenes, S. (2001). Quantification of biofilm accumulation by optical approach. J. Microbial. Meth., 44, 13-26.

Bruij, M.C.M., Venhuis, L.P., Jenner, H.A., Daniels, D.G. and Licina, G.J. (2003). Biocide optimization using an on-line biofilm monitor. Website www.kema-kps.nl

Characklis, W.G. and Marshall, K.C. (1990). Biofilms, Wiley, USA, pp. 55-397. 
Christiani, P., Perboni, G., Hillbert, L., Mollica, A. and Gubner, R. (2002). Experiences on MIC monitoring by electrochemical techniques. Preprints of the International Specialised Conference on Biofilm Monitoring, Porto, Portugal, pp. 197-200.

Cloete, T.E., Jacobs, L. and Brozel, V.S. (1998). The chemical control of biofouling in industrial water systems. Biodegr, 9, $23-37$.

Giao, M.S., Montenergo, M.I. and Vieira, M.J. (2003). Monitoring biofilm formation by using cyclic voltammetry - effect of the experimental conditions on biofilm removal and activity. Wat. Sci. Tech., 47(5), 51-56.

Gilbert, P., McBain, A.J. and Rickard (2003). Formation of microbial biofilm in hygienic situations: a problem of control. Int. Biodeterior. Biodegr., 51, 245-248.

Heydorn, A., Nielsen, A.T., Hentzer, M., Sternberg, C., Givskov, M., Ersbøll, B.K. and Molin, S. (2000). Quantification of biofilm structures by the novel computer program COMSTAT. Microbiol., 145, 2395-2407.

Hilal, N. and Bowen, W.R. (2002). Atomic force microscope study of the rejection of colloids by membrane pores. Desalination, 150, 289295.

Jacobs, L., De Bruyn, E.E. and Cloete, T.E. (1996). The Use of Biodispersant Available for Biofouling Control in Industrial Water Systems. WRC Project No. 592/1/97.

Johnston, M.D. and Jones, M.V. (1995). Disinfection tests with intact biofilms: combined use of the Modified Robbins Device with impedance detection. J. Microbiol. Meth., 21, 15-26.

Lazarova, V. and Manem, J. (1995). Biofilm characterization and activity analysis in water and wastewater treatment. Wat. Res., 29(10), 2227-2245.

Lewandowski, Z. and Beyenal, H. (2003). Biofilm monitoring: a perfect solution in search of a problem. Wat. Sci. Tech., 47(5), 9-18.

Morton, L.H.G., Greenway, D.L.A., Gaylarde, C.C. and Surman, S.B. (1998). Consideration of some implications of the resistance of biofilms to biocides. Int. Biodeterior. Biodegr., 41, 247-259.

Schmid, T., Panne, U., Adams, J. and Niessner, R. (2004). Investigation of biocide efficacy by photoacoustic biofilm monitoring. Wat. Res., 38, 1189-1196.

Schulte, S., Winender, J. and Flemming, H.-C. (2005). Efficacy of biocides against biofilms. In Directory of Microbiocides for the Protection of Materials ed W Paulus, Kluwer, Amsterdam.

Staudt, C., Horn, H., Hempel, D.C. and Neu, T.R. (2003). Specific measurements in biofilms., Presented at IWA International Biofilm Conference, Cape Town, SA.

Stoodley, P., Cargo, R., Rupp, C.J., Wilson, S. and Klapper, I. (2002). Biofilm material properties as related to shear-induced deformation and detachment phenomena. J. Indust. Microbial. Biotech., 29, 361-367.

Tamachkiarow, A. and Flemming, H.-C. (2003). On-line monitoring of biofilm formation in a brewery water pipeline system with a fibre optical device. Wat. Sci. Tech., 47(5), 19-24.

Wanner, O. and Morgenroth, E. (2004) Biofilm modeling with AQUSIM. Wat. Sci. Tech., 49(11-12), 137-144. 